\title{
A Critical Analysis of Active Learning and an Alternative Pedagogical Framework for Introductory Information Systems Courses
}

\author{
John R. Drake \\ Department of Management Information Systems, \\ East Carolina University, Greenville, NC, USA
}

\author{
drakejo@ecu.edu
}

\section{Executive Summary}

Active learning has been championed in academic circles as the pedagogical fix to boring lectures typically found in introduction to information systems courses. However, the literature on active learning is mixed. In this paper, we critically examine active learning research and discover a misplaced emphasis leading to paradoxical findings in four areas. First, creating activities for cognitive engagement is not unique to active learning. Second, the amount of instructor led control and direction is often glossed over, leaving a vague impression as to how much is necessary. Third, out of class activities are often ignored when they also accomplish the same effects for the same reasons. Fourth, an over-emphasis on techniques rather than outcomes renders active learning bound to means and not to ends. The proper end should be the meaningful learning of the course objectives.

We offer an alternative pedagogical framework for evaluating classroom techniques based on philosophic, psychological, and pedagogical research. Ausubel's Assimilation Learning Theory fits this research with a focus on meaningful learning of classroom objectives. In order to achieve meaningful learning of new concepts, an instructor must accomplish four things: (1) clearly define the concepts, (2) provide proto-typical examples, (3) integrate the concepts within the students' knowledge, and (4) motivate the students to want to learn. Application of this pedagogical framework to introductory information systems classes provides a basis for evaluating classroom techniques and increasing meaningful learning. Turning the theory into practice, we propose three different ways to teach a Decision Support System module within an information systems course. Each approach is consistent with the meaningful learning framework. Those three approaches include the traditional lecture format, an activity based format consistent with active learning, and a case study based format which serves as a hybrid between passive and active learning techniques. For each approach, we highlight how the class structure, examples, and resources can help instructors create a meaningful learning experience for their students.

Material published as part of this publication, either on-line or in print, is copyrighted by the Informing Science Institute. Permission to make digital or paper copy of part or all of these works for personal or classroom use is granted without fee provided that the copies are not made or distributed for profit or commercial advantage AND that copies 1) bear this notice in full and 2) give the full citation on the first page. It is permissible to abstract these works so long as credit is given. To copy in all other cases or to republish or to post on a server or to redistribute to lists requires specific permission and payment of a fee. Contact Publisher@InformingScience.org to request redistribution permission.
Keywords: meaningful learning, active learning, introduction to information systems, decision support systems, assimilation learning theory

\section{Introduction}

Active learning - loosely defined as instructional methods that place the responsibility of learning on learners - has gained considerable attention in higher 
education (Prince, 2004), particularly within business programs (Auster \& Wylie, 2006; Heriot, Cook, Jones, \& Simpson, 2008). Heralded as a means of helping students become engaged in the learning process, it promises to create classroom environments where students can not only obtain knowledge but also apply that knowledge in ways similar to those they will face in their career. This pedagogical technique is accomplished through talking, reading, writing, and reflection. Active learning contrasts with passive learning, which typically involves traditional lecture formats or reading assignments. Passive learning continues to be a mainstay in many Introduction to Information System (IIS) classes (Pridmore, Bradley, \& Mehta, 2010). Traditional lecture format often challenges students' attention span, resulting in a rapid drop-off in the retention of class topics (Hartley \& Davies, 1978; Wankat, 2002). Given the promises for active learning, it seems natural that we should consider its application to IIS courses.

However, little research shows the application of active learning to IIS courses. As a required course for most undergraduate business majors, this may be the only introduction business students receive to information system concepts. Many students enter college with little understanding or appreciation of information technology (Ballou \& Huguenard, 2008), yet they are required to use them extensively upon entering the work force. The challenges of presenting information technology content effectively are anything but trivial. With technological change accelerating at an exponential rate, much of what students learn will be obsolete by the time they graduate from their programs. Compounded with the rate of change is the frequent lack of interest in information systems (Ballou \& Huguenard, 2008). This results in frustration for the instructor to teach a subject well, along with a frustration from the student in learning disconnected facts. Given these problems, it is reasonable to ask if active learning is an appropriate means of improving IIS instruction.

In this paper, we examine the application of active learning to IIS courses. By examining philosophical, psychological, and education-based literature, we challenge the active learning pedagogical framework and suggest an alternative framework would be more effective at presenting content in IIS courses. The criteria for a successful framework are that it is universal to all contexts, it is self-contained, and it is consistent with epistemological and psychological facts. Our objective is threefold: (1) to critically analyze active learning techniques, (2) to explore how and why these techniques succeed or fail in producing meaningful learning of IIS concepts, and (3) to provide an example of Assimilation Learning Theory (ALT) to a Decision Support Systems (DSS) module within an IIS course.

In the next section, we review active learning research, identify its limitations, and suggest a new approach based on epistemological and psychological foundations necessary to support meaningful learning. Based on this foundation, we discuss implications in IIS courses and provide example implementation.

\section{Background}

Many credit educational philosopher Dewey (1959), with his learning by "doing" philosophy, and child psychologist Piaget (Gallagher \& Reid, 2002), with his "active" approach to learning, for laying the theoretical foundation of the active learning movement. Unfortunately, active learning has a history of vague definitions and nebulous descriptions that make discussion of this concept difficult (Bonwell \& Eison, 1991; Prince, 2004). Examples of active learning include in-class discussion, case study discussion, short written exercises, role-playing, games, hands-on activities, debate, academic service learning, experimental learning, and discovery learning. Classroom activities that generally fall into the passive learning category include lectures, reading textbooks, and traditional homework. In a much cited U.S. government report (Bonwell \& Eison, 1991), the following themes were identified in active learning education: (1) students are involved in more than listening, (2) less emphasis is placed on transmitting information and more on developing 
students' skills, (3) students are involved in higher-order thinking (analysis, synthesis, and evaluation), (4) students are engaged in activities (reading, discussing, or writing), and (5) greater emphasis is placed on students' exploration of their own attitudes and values. These trends led Bonwell and Eison (1991) to define active learning as activities that "involve students in doing things and thinking about the things they are doing." Because this government report is very influential in funding educational and pedagogical research projects, it serves as the starting point of our analysis.

There are several problems with this conception of active learning. We will address four. First, what does it mean to involve students in "doing" things? Does "doing" something require physical activity? There is evidence that physical activity may be harmful to learning concepts (Mayer, 2004), suggesting that activity in and of itself does not support learning. It must be well designed cognitive activities that promote thoughtful engagement around learning outcomes (Mayer, 2004). Yet, there is nothing inherent in typical active learning activities that suggest they alone provide thoughtful engagement. Some so called passive learning activities can promote thoughtful engagement. Many of us remember instances of thought provoking lectures or spell binding books. Such "passive" activities keep audiences cognitively engaged for long periods when structured appropriately. Books on study methods suggest students can improve their active engagement during lectures to help improve retention (Locke, 2008). If this is in fact true, then passive learning can cause thoughtful engagement if students are properly motivated and skilled at thinking while taking notes. There is no evidence that all active learning activities provide thoughtful engagement. While it may be a goal of some activities, the framework does not distinguish between activities that do and those that do not.

A second problem with the above conception is that it leaves unanswered how much control and guidance the instructor should have in the class. At the extreme in pure active learning, sometimes referred to as inquiry learning, the instructor involvement is minimal to non-existent. In one such pure active learning, called discovery learning, students engage with materials without any instructor support, guidance, or influence. Research efforts found that discovery learning is inferior to guided learning in gaining knowledge about the subject (Kirschner, Sweller, \& Clark, 2006; Mayer, 2004). Considering that discovery learning is asking students to discover principles inductively that experts in the field struggled years to discover, the struggle to gain knowledge makes sense. Interestingly, in a widely cited government policy statement noted above, no pure active learning research was included. In cases where active learning shows improved student retention of class materials, the instructor still provided a lecture and guided the activities (Astin, 1993; Di Vesta \& Smith, 1979; Hake, 1998; Ruhl, Hughes, \& Schloss, 1987). Therefore, the notion that some active learning is beneficial may stand, but more may not be better. Unfortunately, active learning proponents do not provide a means of evaluating how much guided instruction is ideal or necessary.

Third, many active learning proponents do not consider engaging out-of-class activities as part of the active learning tradition (Bonwell \& Eison, 1991; Prince, 2004). Given the definition of active learning above, there is little justification for this exception. Challenging homework problems, online discussion boards, or written assignments can provide the same benefits of in-class activities. In each case, students engage in higher order thinking activities in order to develop skills, reflect on their experiences, or think about class discussions. These activities generally promote thoughtful engagement around learning outcomes.

Lastly, there is a focus on techniques for instruction, rather than outcomes. Although active learning proponents may strongly counter such a claim by asserting that active learning does include higher order thinking and reflection, too often they do not specify to what end. Collaboration and cooperation work only if students do not fumble with new concepts and principles. Classroom discussions may not be helpful if misconceptions continue unchecked and propagate into later 
discussions. Active learning proponents may claim to support learning objectives, but the discussion always focuses on the dichotomy between active and passive techniques. Without a clear focus on the ends, well-meaning instructors may mis-apply techniques in the classroom. Active learning provides no standard for judging the appropriateness of one technique over another.

To unravel these paradoxes, it is necessary to dig deeper into the causes of successes and failures in learning and understanding concepts. Why is active learning effective in certain contexts but not in others? Why are some lectures engaging and others boring? Is there some common denominator to explain success or failure in teaching concepts? In the next section, we explore the epistemological and psychological foundations of concepts, conceptual development, and pedagogy. From this, we propose an alternative framework for evaluating classroom techniques in IIS and provide three examples of this framework applied to a Decision Support System module within an IIS course.

\section{Epistemological and Psychological Foundation of Concepts}

From an early age, children develop an understanding of the world. This process starts with recognition of patterns from their perceptions. Similarities and differences between characteristics of real world objects evolve into ever more complex identifications. Concepts are formed when specific essential characteristics are subsumed into a single mental unit with an attached word (Rand, 1990). By forming concepts, individuals create mental groupings that economize their thinking process such that they can think about hundreds or thousands of specific entities without having to keep them all in mind at the same time. By thinking the concept "computer", an individual integrates references to the millions of computers in the world without having to keep all of them in his short-term memory at the same time. Without the economizing nature of concepts, an individual would have to try to include all possible variations of a concept in his mind at the same time, an impossible feat given the limitations of our working memory (Cowan, 2001) and the diversity of objects in the world.

A hierarchy of concepts emerges. Simple concepts closely related to perceptions of objects and relationships in the real world form the bottom, and complex concepts dealing with abstract generalizations form the top. In biology, the hierarchy of concepts explicitly categorizes every living thing using the taxonomy species, genus, family, order, class, phylum, and kingdom. Each successive level in the taxonomy includes a larger number of specific real world life forms, encapsulating concepts that are more abstract. Biology also recognizes a number of concepts for relationships between life forms, such as simple predator-prey relationships, to more complex parasitic and symbiotic relationships, to very complex ecosystem relationships. The same hierarchy exists in every domain of knowledge.

As individuals mature, conceptual understanding of reality develops with more precise definitions, better understanding of relationships between concepts, and finer differentiation of subconcepts. The role of education is to facilitate this growth in conceptual understanding. As learners move from novice to expert, they learn new concepts, establish more relationships between concepts, and identify more examples of concepts. Meaningful long-term learning only takes place when concepts introduced build upon the knowledge base already established (Novak, 2002). Understanding a domain of knowledge requires the integration of new concepts within their entire semantic network (Regehr \& Norman, 1996). Without this integration, ideas are quickly forgotten and of little use to the learner in future applications.

\section{An Alternative Pedagogical Framework}

An alternative pedagogical framework empirically shows large improvements in long-term meaningful learning. This approach identifies a continuum from meaningful learning to rote learning, 
first identified by educational psychologist Ausubel (1968) in his Assimilation Learning Theory (ALT) and enhanced by Novak (2010). According to Ausubel, there are four things necessary for meaningful learning: (1) new concepts are carefully defined, (2) new concepts are related to real world examples, (3) new concepts are integrated with the learner's prior knowledge, and (4) new concepts are motivating to the learner (Novak \& Cañas, 2008). Meaningful learning requires well-organized relevant examples and an emotional commitment by the learner to integrate new knowledge. Students must want to, be able to, and be shown the relevant material to learn course objectives by integrating material into existing concepts, progressively differentiating concepts into sub-concepts, and creating new superordinate concepts (Novak, 2010). Meaningful learning fails when students are not properly motivated, when definitions are unclear or ambiguous, when insufficient or irrelevant examples are shown, or when concepts are not integrated with students' current knowledge. In rote learning, the learner memorizes a conceptual definition and does not or cannot apply it to their prior knowledge. Rote learning often results from little or no relevant knowledge or examples from which to base understanding and from no emotional commitment for integration (Novak \& Cañas, 2008). Such rote learning can be retained in memory long enough to pass an exam, but because it is not integrated with existing knowledge it is soon forgotten.

While the meaningful/rote learning differentiation focuses on the transmission of knowledge from instructor to student, ALT is much broader. Figure 1 highlights our understanding of this theory. All learning materials should start with an assessment of prior knowledge of the students. Ausubel (1968) states the most important factor impacting learning is what the learner already knows. With an assessment of learner's prior knowledge, the instructor can construct the learning environment and materials that build on what the students already know and understand, thereby limiting repeat materials while avoiding unwarranted assumptions of prior understanding. This assessment should be ongoing throughout the class. The instructor should not assume that just because the material was presented that the learner understands it. If the instructor proceeds to new material without verifying the conceptual understanding of earlier concepts, it becomes increasingly difficult for the learners to understand the new concepts when those new concepts are based on preceding ones.

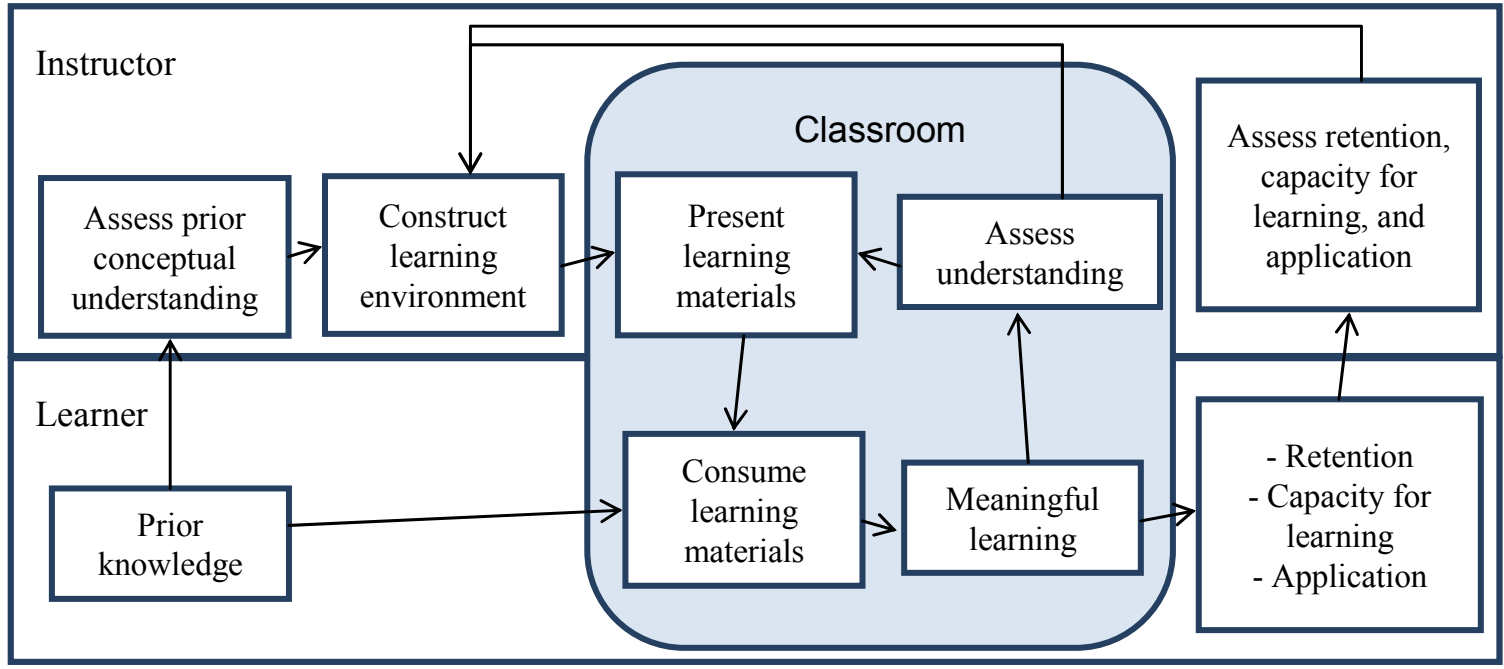

Figure 1. Our understanding of ALT 
Assessing rote learning versus meaningful learning can be difficult during the class. The ultimate assessment of meaningful learning is (1) the long-term retention of concepts, (2) differentiability of related materials, (3) capacity to learn unrelated subjects, and (4) application to new problems and contexts (Novak, 2010). Post-hoc assessment provides a means to evaluate the original learning environment for possible improvements. Because of the complexity of this framework, we focus on the presentation of learning materials and its four prerequisites to meaningful learning: definitions, examples, integration, and motivation.

\section{Implications}

Active learning in education provides some benefits to conceptual development, but only to the extent it facilitates meaningful learning. Active learning techniques should be considered as part of a toolbox that can help facilitate mastery of materials, but only if used appropriately. When comparing active/passive learning to meaningful/rote learning, we can envision them as orthogonal, such that active learning can be meaningful or rote just as passive learning can be meaningful or rote. Below, we discuss the application of this framework and the four assessment criteria for meaningful learning to an IIS context.

The first place IIS instructors and researchers should focus is discovering what incoming students already know. To the best of our knowledge, little research exists on student knowledge of information systems before entering an IIS course. We should not assume students are familiar with many of the technologies discussed in a particular course module. In order to relate discussion to new technologies and theories, discussion should start with everyday contexts familiar to students. These might be common problems they face, real-life dilemmas they can relate to, or tools they currently use to achieve their goals. By starting at these points, instructors can simultaneously motivate, integrate, and identify examples. The motivation comes from identifying a problem in their lives that needs attention. Integration comes from relating their personal problems with technology that can fix those problems. The examples are identified by the students themselves, although the instructor may add additional examples to deepen the discussion further.

Because motivation is major issue in IIS (Ballou \& Huguenard, 2008), students must be presented with a convincing immediate need that IS can help resolve. The lack of interest in IS stems, in part, from a lack of understanding of the relevance of the subject to their current and long-term success. Students, who have grown up with computers, take them for granted. Unless the instructor can effectively demonstrate the need, students may struggle to identify that purpose for themselves. Techniques, such as problem based instruction, have shown some success in increasing motivation for IS concepts (Mykytyn, Pearson, Paul, \& Mykytyn, 2008).

IIS instructors and researchers should build each course module upon prior work. While a systematic development of skills and knowledge over time is often acknowledged in MIS programs (Harper \& Harder, 2009), a means of identifying the proper order is too often neglected. Likewise, the sequence of course modules in IIS should systematically develop knowledge of IS concepts over time. Instructors have several optional approaches to sequencing modules. One method would be to start with abstract concepts and progressively differentiate sub-concepts. For example, they could start discussing the general concept "computer", which leads to a discussion of the different types of computers used for different, specialized purposes. Another method is to start with less abstract concepts close to concretes and successively introduce more abstract concepts. Here, instructors might start the semester by presenting information system successes and failures in order to establish basic principles for information systems success.

However, abstract and complex subjects should be covered after simple subjects are meaningfully learned. If explaining networks, discussion should start with simple home networks or build on the students' understanding of the internet. If discussing enterprise resource planning, examples 
could start with point of sales systems, which most students can relate to at least indirectly when they purchase items from stores. A discussion of IT architecture or IT strategy is beyond the understanding of most students entering an introduction to IS class, as few have worked extensively with computers in an organizational context or had a class in business strategy. Including a discussion of strategy early in an introductory IS course would be far too difficult for many learners to apply to their previous knowledge. Prior to learning about IT strategy, students should meaningfully learn about computers, data processing, infrastructure, and the need for long-term IT planning from which to build a rich and meaningful understanding of why IT strategy is important for continued innovative success.

In establishing the proper order of conceptual coverage, ALT suggests that simple concepts precede complex concepts. Unfortunately, this is too often neglected (VanDamme, 2006). Determining which concepts are simple and which are complex stems from the historical fact that simpler concepts are discovered prior to complex concepts. There is a necessary precondition that all complex concepts necessitate the discovery of simple concepts first. In mathematics, the discovery of algebra preceded the discovery of calculus. It would have been impossible for Newton or Leibniz to create calculus if algebra was unknown by these men. As mathematics educators can relate, it is impossible for students to meaningfully learn calculus without first having mastered algebra. This same approach can be used for identifying the order of conceptual coverage in class.

For example, there were large scale accounting machines in businesses prior to computers. These accounting machines handled business problems requiring massive number crunching. However, accounting machines lacked the flexibility to handle the increasingly diverse types of calculations required by large businesses. The ability to program computers gave them an advantage over traditional accounting machines by allowing for flexibility in usage. This historic fact suggests that data processing needs of businesses should be discussed prior to discussing computers and their functionality.

History will not provide all the answers to content inclusion or ordering of conceptual discussions. Some historical events have little influence on subsequent events. Discussing such events in the curriculum does not help students build meaningful understanding of concepts. Additionally, there will likely be some optional ordering schemes when concepts are completely independent or partially interdependent and arising simultaneously. There will also be cases where names of concepts have changed over the years, such as the term computer, which originally referred to people who computed numbers but now refers exclusively to a specific electronic technology. Our role as educators is to pull all of this information together, determine what is relevant, organize it, and present it in a context appropriate for meaningful learning.

\section{Theory into Practice}

One area where many IIS textbooks have inadequate concept development is in DSS (Hassan \& Becker, 2007). Given the limitation of the textbooks, the in-class experience is especially critical for conceptual understanding. DSS includes a variety of tools, including model-driven, datadriven, document-driven, rule-driven, and communication-driven applications (Power \& Sharda, 2009). Applying the meaningful learning framework suggests that the class module should (1) define the terms clearly, (2) integrate the concepts within the student conceptual framework, (3) provide prototypical examples, and (4) motivate the learner. Defining the terms clearly is often not an issue and can be done in conjunction with describing the broad categories. For example, Power and Sharda (2009) define the 5 categories as: 
- "Model-driven DSS emphasize access to and manipulation of a model." (p. 1542)

- "Data-driven DSS emphasize access to and manipulation of a large database of structured data, especially a static time-series of internal company data and, in some systems, external data." (p. 1542)

- "A Document-driven DSS integrates a variety of storage and processing technologies to provide complete document retrieval and analysis." (p. 1542)

- "Rule-driven DSS can suggest or recommend actions to decision makers." (p. 1543)

- Communication-driven DSS “includes communication and collaboration decision support technologies that do not fit conveniently within three DSS types..." (p. 1543)

How and when these definitions are presented will depend on the context of the class. We provide three possible approaches to teaching this module within the meaningful learning framework; one using traditional lecture techniques, one using active learning techniques, and one using case study analysis. All three approaches follow the basic course learning goals and order of coverage (Figure 2). First, students must be motivated by seeing real world decision making problems. Then, they must see that there are activities that can be done to overcome these limitations. Lastly, they must see that a technological solution exists and what that solution is called.

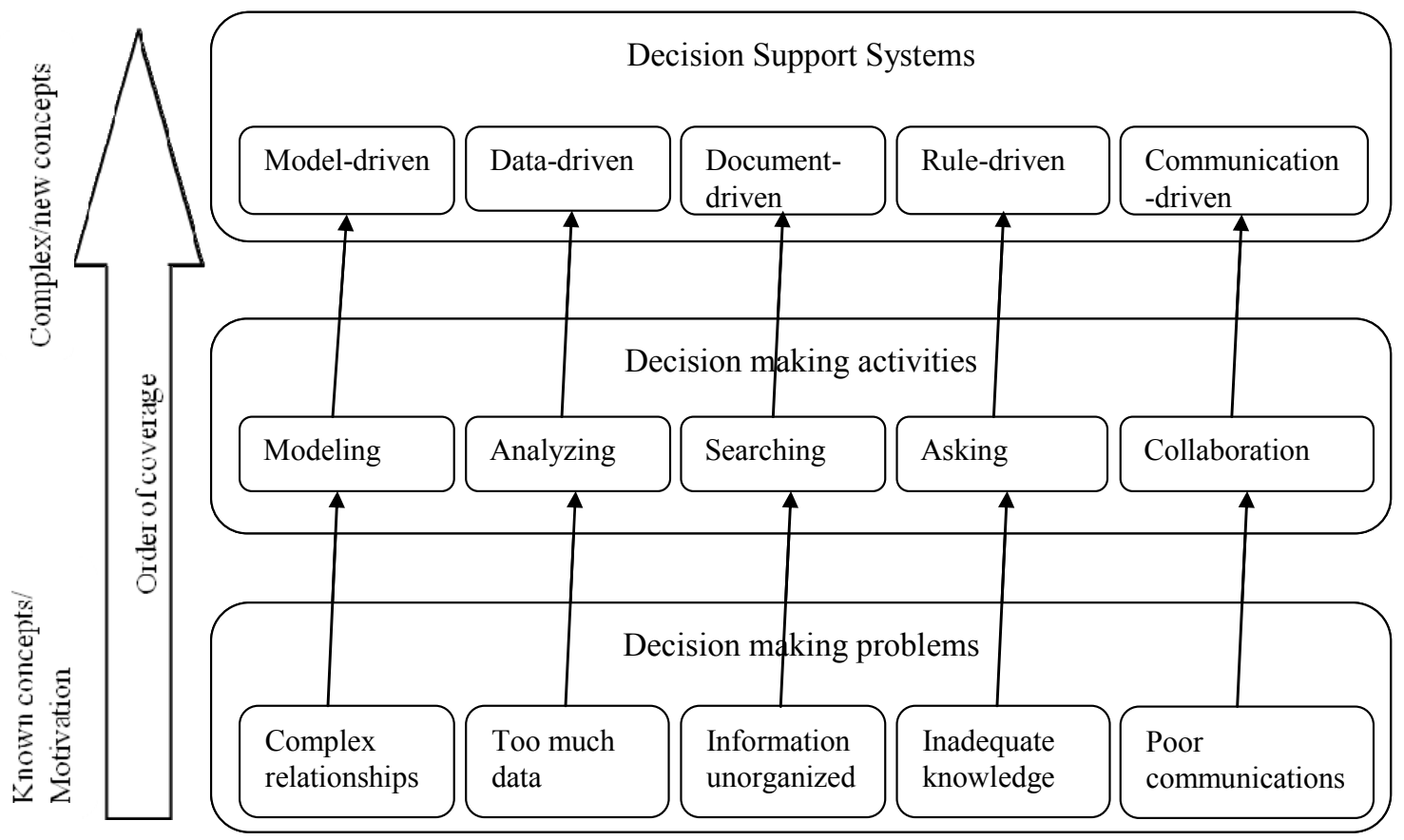

Figure 2. DSS Module learning goals and order of coverage

\section{Example 1. Traditional Lecture Approach}

While lectures excel at delineating definitions, providing examples, and having a large capacity for integrating concepts, the danger is that students are not motivated and quickly lose interest. One technique to motivate students during lectures is with story-telling (Buckler \& Zien, 1996). The instructor can introduce the lecture with a series of short stories demonstrating the cognitive 
limitations of humans in five different contexts. In keeping with ALT, these stories should relate to the learner's prior knowledge. For example, short stories could include:

1. Weather - One afternoon you decide to go shopping. As you climb out of your car, you see that it is bright and sunny, without a cloud in the sky. You decide to leave your umbrella in the car so that you do not have to hassle with it while shopping. Two hours later, you remember that you have a dinner date with a friend. As you head back outside, the lovely weather has turned into a torrential downpour. If only you could have predicted the weather better...

2. University selection - As you approach your senior year in high school, you decide that college is the right path for you. However, when you start looking at universities, you realize that there are 1000s of them, each with their own set of considerations. Tuition, class size, programs of study, number of students, graduate salaries, average SAT scores, expenditures per student, reputation, private versus public, graduation rates, average student debt, location, faculty credentials, athletics, cultural experience, fraternities, sororities, and more. How can you make sense of all that data?

3. Buying a used car - After saving your money for the last two years, you finally have enough to buy a used car. But you are having problems. You know of a few dealerships around town, but is that the entire selection? You are sure that a list of dealerships must exist, but how can you find it? As you start looking at cars, you remember that there is a book that lists average car prices for various models, years, and conditions. How can you find those documents? How can you find the best value on a car?

4. Medical problem - On your first day of vacation in a foreign country, you wake up dizzy and nauseous. You are concerned that your symptoms may be more than just jet lag but do not want to have to pay for a hospital visit if you can avoid it. Unfortunately, it's the weekend and your doctor is not answering your calls. Is there some way you can check to see if these symptoms are just jet lag? Or should you be more concerned?

5. Group project dilemma - In one of your classes, the instructor has asked you to complete a project with 3 other students. But you live and work an hour away from school and cannot meet on campus when the other three students are available. With the deadline rapidly approaching, how are you going to complete the project?

Each of these stories highlights a different problem understandable to students (even if they have never personally experienced it) that requires an activity that's limited by our cognition. After presenting these stories, the lecture can address how information systems can overcome each of these limitations. At this point, definitions of the DSS categories can be presented, highlighting the similarities and differences between each category. The lecture could then transition into a discussion of related business problems and tools that facilitate solving these problems. To keep students cognitively involved, this part should not consist of a series of lists, but could include mini-cases, short stories, or demonstrations. The lecture should also provide examples that integrate with the various functional business units - finance, accounting, marketing, operations management, human resources, etc. Table 1 summarizes examples that might be used. 


\begin{tabular}{|c|c|c|c|}
\hline \multicolumn{4}{|c|}{ Table 1. Lecture examples } \\
\hline & $\begin{array}{l}\text { Motivating } \\
\text { examples }\end{array}$ & $\begin{array}{l}\text { Business problem } \\
\text { examples }\end{array}$ & Tools \\
\hline Model-driven & Weather prediction & $\begin{array}{l}\text { Economic modeling } \\
\text { Marketing what-if } \\
\text { analysis } \\
\text { Production } \\
\text { optimization }\end{array}$ & $\begin{array}{l}\text { Excel } \\
\text { Simulations } \\
\text { Mathematical formulas } \\
\text { Statistical formulas }\end{array}$ \\
\hline Data-driven & $\begin{array}{l}\text { Picking the ideal } \\
\text { university }\end{array}$ & $\begin{array}{l}\text { Discover trends in } \\
\text { sales } \\
\text { Discover trends in } \\
\text { logistics }\end{array}$ & $\begin{array}{l}\text { Data warehouse } \\
\text { Data mining } \\
\text { Business intelligence } \\
\text { Excel }\end{array}$ \\
\hline Document-driven & Buying a used car & $\begin{array}{l}\text { Knowledge } \\
\text { management } \\
\text { Human resource } \\
\text { documentation } \\
\text { Capturing best } \\
\text { practices }\end{array}$ & $\begin{array}{l}\text { Knowledge management } \\
\text { systems } \\
\text { Intranets } \\
\text { Search engines }\end{array}$ \\
\hline Rule-driven & $\begin{array}{l}\text { Diagnosing medical } \\
\text { problems }\end{array}$ & $\begin{array}{l}\text { Loan approval } \\
\text { process } \\
\text { Troubleshooting } \\
\text { complex systems } \\
\text { Mass training }\end{array}$ & $\begin{array}{l}\text { Expert systems } \\
\text { Neural networks } \\
\text { Executive information } \\
\text { systems }\end{array}$ \\
\hline $\begin{array}{l}\text { Communication- } \\
\text { driven }\end{array}$ & $\begin{array}{l}\text { Group project } \\
\text { dilemma }\end{array}$ & $\begin{array}{l}\text { Long distance } \\
\text { meetings } \\
\text { Collaboration on the } \\
\text { same document } \\
\text { Training small } \\
\text { groups } \\
\text { asynchronously }\end{array}$ & $\begin{array}{l}\text { Web conferencing } \\
\text { Email } \\
\text { Social networks } \\
\text { Wiki } \\
\text { Learning management } \\
\text { systems }\end{array}$ \\
\hline
\end{tabular}

\section{Example 2. Active Learning Approach}

As we stated above, one of the strengths of active learning is in motivating, in providing deeper integration, and in keeping students cognitively engaged. The dangers are that definitions may not be clearly specified or that conceptual confusions are not identified and eliminated. Perhaps one of the most direct ways for learners to be motivated while simultaneously witnessing an example is to participate in an activity using a DSS to solve a problem. With that in mind, the following five activities could provide a beginning to a class:

1. "What-if" analysis - Using a pre-populated spreadsheet with built in mortgage rate formulas, students could be challenged to discover what would be their total monthly payment for various specific inputs.

2. Pivot table - Using a pre-populated spreadsheet with fictional sales data for multiple products at multiple stores over several quarters, the students could be instructed to create a pivot table so as to better analyze the data. 
3. Web Search - For document-driven DSS, the instructor could challenge students to find a trivial piece of information on the Internet without using a web search engine, such as how many children did Napoleon Bonaparte father.

4. Neural network - www.20q.net provides an interactive decision support game based on the classic game 20 questions.

5. Web conferencing - If the details are arranged ahead of time, the entire class module could be conducted through a web conferencing tool, such as Blackboard Collaborate, Centra, or Skype.

After completing these activities (summarized in Table 2), the instructor could provide a short lecture on each category, identifying typical business problems and tools used to solve these problems. It is important to clearly articulate the similarities and differences between the various categories of DSS. Lastly, the students could participate in another activity, where they are given several business problems (like those mentioned above in Table 1) and asked as a class to specify which category of DSS could best provide a solution for each problem. This last activity would help students integrate the concepts within their knowledge. Furthermore, misapplied categorization can help identify and eliminate conceptual confusions.

\begin{tabular}{|l|l|}
\hline \multicolumn{2}{|c|}{ Table 2. Active learning activities } \\
\hline & Motivating Activities \\
\hline Model-driven & Performing a "What if" analysis \\
\hline Data-driven & Work with a pivot table \\
\hline Document-driven & Searching the web \\
\hline Rule-driven & Use neural net software \\
\hline Communication-driven & Conduct class using a web conferencing \\
\hline
\end{tabular}

\section{Example 3. Case Study Approach}

Case study analysis provides a blend of traditional passive learning techniques and active learning techniques. The strengths of case studies are that they often cognitively motivate students by explicitly identifying real world business problems, by providing clear examples of a solution, and by integrating the concept with other business concepts. The danger is that the definitions of concepts may not be clearly articulated or that the example is too complex for students to appreciate or analyze. However, these dangers can be overcome with proper training in case study analysis and directed questions during discussion. If following a case study analysis, the instructor must carefully select five different cases studies that highlight the five different categories of DSS (for examples, see Table 3). These cases should be read and analyzed prior to class. The analysis should not only focus on the specifics of each case, but also cross case comparisons. During the class discussion, the instructor often takes on the role of a mediator, asking open-ended questions to facilitate student engagement and participation. To tease out the definitions, the instructor can ask students about the similarities and differences between the tools used to solve their respective case problems. With guided questions, the instructor can lead students to appreciate the different types of decision making activities each system facilitates, thereby opening the opportunity for students to intuitively and meaningfully grasp the DSS categories. 


\begin{tabular}{|l|l|}
\hline \multicolumn{2}{|c|}{ Table 3. Case study examples (from http://dssresources.com/cases/ ) } \\
\hline & Possible Case studies \\
\hline Model-driven & PADAL helps US Navy aircraft land aboard carriers \\
\hline Data-driven & $\begin{array}{l}\text { The George Washington University Data-Driven Decision Support } \\
\text { Project }\end{array}$ \\
\hline Document-driven & $\begin{array}{l}\text { University of Alberta increases timely access to policies and proce- } \\
\text { dures }\end{array}$ \\
\hline Rule-driven & $\begin{array}{l}\text { Business rules drive modernization of legacy transaction systems at } \\
\text { the California Department of Motor Vehicles }\end{array}$ \\
\hline $\begin{array}{l}\text { Communication- } \\
\text { driven }\end{array}$ & $\begin{array}{l}\text { The Space Shuttle Challenger Disaster: A failure in decision support } \\
\text { system and human factors management }\end{array}$ \\
\hline
\end{tabular}

\section{Conclusion}

While active learning offers some hope for increasing conceptual understanding, its lack of appropriate focus leaves it suffering from mixed findings. Refocusing the discussion on ALT enables IIS instructors to develop courses that provide meaningful conceptual development. Consistent with epistemological, psychological, and pedagogical research, concepts cannot be learned in a vacuum, but are dependent upon an integration of concrete experiences and relationships with other concepts, within a proper motivational environment. In contrast, concepts learned in a rote manner quickly vanish from the learner's memory. Developing a hierarchically based conceptual understanding of content is the most appropriate way of promoting meaningful learning. By covering the simple concepts first, instructors can ensure a deeper understanding of ideas necessary for understanding complex ideas later in a course. We provided three examples of this approach for a DSS module in an introduction to information systems class.

\section{References}

Astin, A. (1993). What matters in college?; Four critical years revisited. San Francisco, CA: Josey-Bass.

Auster, E. R., \& Wylie, K. K. (2006). Creating active learning in the classroom: A systematic approach. Journal of Management Education, 30(2), 333-353.

Ausubel, D. P. (1968). Educational psychology: A cognitive view. New York, NY: Holt, Rinehart and Winston.

Ballou, D. J., \& Huguenard, B. R. (2008). The impact of students' perceived computer experience on behavior and performance in an introductory information systems course. Journal of Information Systems Education, 19(1), 87-97.

Bonwell, C. C., \& Eison, J. A. (1991). Active learning: Creating excitement in the classroom. Washington, DC: Education Resource Information Center (ERIC).

Buckler, S. A., \& Zien, K. A. (1996). The spirituality of innovation: Learning from stories. The Journal of Product Innovation Management, 13(5), 391-405.

Cowan, N. (2001). The magical number 4 in short-term memory: A reconsideration of mental storage capacity. Behavioral and Brain Sciences, 24, 87-114.

Dewey, J. (1959). Dewey on education. New York, NY: Bureau of Publications, Teachers College, Columbia University. 
Di Vesta, F., \& Smith, D. (1979). The pausing principle: Increasing the efficiency of memory for ongoing events. Contemporary Educational Psychology, 4.

Gallagher, J. \& Reid, K. (2002). The learning theory of Piaget and Inhelder. Lincoln, NE: Authors Choice Press

Hake, R. (1998). Interactive-engagement vs. traditional methods: A six-thousand-student survey of mechanics test data for introductory physics courses. American Journal of Physics, 66(1), 64.

Harper, J. S., \& Harder, J. T. (2009). Assurance of learning in the MIS program. Decision Science Journal of Innovative Education, 7(2), 489-504.

Hartley, J., \& Davies, I. K. (1978). Note taking: A critical review. Innovations in Education and Teaching International, 15(3), 207-224.

Hassan, N. R., \& Becker, J. D. (2007). Uncovering conceptual gaps in introductory IS textbooks. Journal of Information Systems Education, 18(2), 169-182.

Heriot, K. C., Cook, R., Jones, R. C., \& Simpson, L. (2008). The use of student consulting projects as an active learning pedagogy: A case study in a production/operations management course. Decision Sciences Journal of Innovative Education, 6(2), 463-481.

Kirschner, P. A., Sweller, J., \& Clark, R. E. (2006). Why minimal guidance during instruction does not work: An analysis of the failure of constructivist, discovery, problem-based, experiential, and inquirybased teaching. Educational Psychologist, 41(2), 75-86.

Locke, E. A. (2008). Study methods \& motivation: A practical guide to effective study (2nd ed.). Irvine, CA: The Ayn Rand Bookstore.

Mayer, R. E. (2004). Should there be a three-strikes rule against pure discovery learning? American Psychologist, 59(1), 14-19.

Mykytyn, K., Pearson, A., Paul, S., \& Mykytyn, P. P. (2008). The use of problem-based learning to enhance MIS education. Decision Sciences Journal of Innovative Education, 6(1), 89-113.

Novak, J. D. (2002). Meaningful learning: The essential factor for conceptual change in limited or inappropriate propositional hierarchies leading to empowerment of learners. Science Education, 86(4), 548-571.

Novak, J. D. (2010). Learning, creating, and using knowledge (2nd ed.). New York, NY: Routledge.

Novak, J. D., \& Cañas, A. J. (2008). The theory underlying concept maps and how to construct and use them. Technical Report IHMC CmapTools 2006-01 Rev 01-2008: Florida Institute for Human and Machine Cognition.

Power, D. J., \& Sharda, R. (2009). Decision support systems. In S. Y. Nof (Ed.), Springer handbook of automation (pp. 1539-1548). New York, NY: Springer.

Pridmore, J. L., Bradley, R. V., \& Mehta, N. (2010). Methods of instruction and learning outcomes: A theoretical analysis of two approaches in an introductory information technology course. Decision Science Journal of Innovative Education, 8(2), 289-311.

Prince, M. (2004). Does active learning work? A review of the research. Journal of Engineering Education, 93(3), 223-231.

Rand, A. (1990). Introduction to objectivist epistemology (2nd ed.). New York: Meridian.

Regehr, G., \& Norman, G. (1996). Issues in cognitive psychology: Implications for professional education. Academic Medicine, 71(9), 988-1001.

Ruhl, K., Hughes, C., \& Schloss, P. (1987). Using the pause procedure to enhance lecture recall. Teacher Education and Special Education, 10, 14-18.

VanDamme, L. (2006). The hierarchy of knowledge: The most neglected issue in education. The Objectivist Standard, 1(1). 
Wankat, P. (2002). The effective efficient professor: Teaching, scholarship and service. Boston, MA: Allyn and Bacon.

\section{Biography}

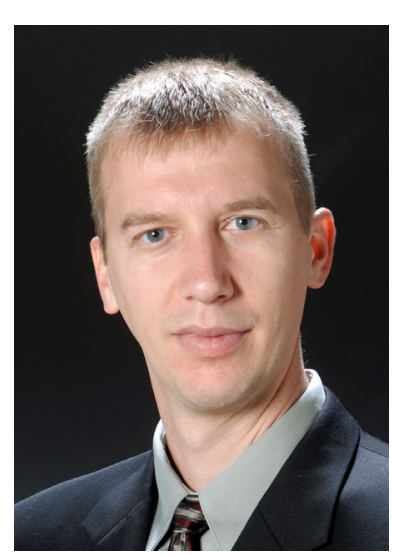

John Drake is an Assistant Professor of Management Information Systems at East Carolina University. He received his doctorate in MIS at Auburn University. His research has appeared in the International Journal of Integrated Supply Management and Journal of Information Technology Theory and Application, and various national and international conferences. His current research interests include online auctions, human computer interaction, and ethics. Prior to academy, John was an IT professional and consultant for 5 years. 